\title{
Influência do Uso do Poliol Reciclado Obtido pela Glicólise na Preparação da Espuma Rígida de Poliuretano
}

\author{
Elio Lopes \\ Mestrado Profissional em Engenharia Mecânica, IST \\ Daniela Becker \\ Centro de Ciências Tecnológicas, UDESC \\ Mestrado Profissional em Engenharia Mecânica, IST
}

\begin{abstract}
Resumo: Um dos grandes problemas da atualidade é o destino final adequado dos materiais, que não podem ser reutilizados no processo de origem. Dentre os resíduos estão as espumas rígidas de poliuretanos (PUR), que são materiais com ampla aplicação, mas apresentam dificuldades de reaproveitamento tecnológico por serem materiais termorrígidos. O objetivo deste trabalho é aplicar o processo de reciclagem química por glicólise e utilizar o poliol reciclado, produto da reação de glicólise, como parte da matéria prima para formação de espumas rígidas de poliuretano e analisar suas propriedades físicas, mecânicas e térmicas. A formação das células da espuma com poliol reciclado foi avaliada por microscopia eletrônica de varredura (MEV). Os resultados mostram que, nas condições estudadas, não há perdas das propriedades mecânicas e térmicas da espuma de PUR com a utilização de poliol reciclado, satisfazendo as necessidades para aplicação na produção de refrigeradores domésticos.
\end{abstract}

Palavras-chave: Reciclagem química, glicólise, espuma rígida de poliuretano.

\section{Influence of the Use of Recycled Polyols Obtained by Glycolysis on the Preparation of Rigid Polyurethane Foam}

\begin{abstract}
One of the major problems is the appropriate final destination of the materials or waste that can not be reused in the original process. Among the residues are rigid polyurethane foams, which are widely applied but difficult to reuse because they are thermosetting materials. The aim of this paper is to apply a chemical recycling process, glycolysis, and use the recycled polyol, product of glycolysis reaction, as part of the raw material for the formation of rigid polyurethane foams. Their mechanical properties and thermal conductivity were analyzed. The formation of foam cells with recycled polyol were evaluated by scanning electron microscopy (MEV). The results show that there is no loss of mechanical and thermal properties of PUR foam, satisfying the requirements for the production of domestic refrigerators.
\end{abstract}

Keywords: Polyurethane, chemical recycling, glycolysis, rigid polyurethane foam.

\section{Introdução}

Um dos problemas mais discutidos na atualidade é o gerenciamento adequado da disposição final de materiais que não são reutilizáveis no seu processo de origem, especialmente os polímeros termorrígidos, por apresentarem uma estrutura química complexa, com longas cadeias cruzadas com baixa taxa de degradação e que são oriundos de fontes não renováveis. Um exemplo deste problema é a espuma rígida de poliuretano (PUR) que apresenta excelentes propriedades térmicas para isolamento térmico e provê alta resistência estrutural para refrigeradores e freezeres domésticos ${ }^{[1]}$. Este material é um termorrígido e possui uma estrutura altamente reticulada com células fechadas, baixa densidade e baixa condutividade térmica. No mercado brasileiro aproximadamente $58 \%$ em volume deste poliuretano está voltado para o segmento de refrigeração doméstica ${ }^{[2]}$. Atualmente, a indústria de refrigeração doméstica tem gerado grandes volumes de rejeitos de PUR em função do controle e desvios de processo, do controle da qualidade de espuma, dos programas governamentais brasileiro de trocas incentivadas de refrigeradores para redução do consumo de energia elétrica, do incentivo da criação de trabalho e renda com a isenção de impostos para produtos "verdes", e por todos os motivos inerentes a este setor industrial. As indústrias de refrigeradores domésticos no Brasil utilizam como meio para o destino deste material a deposição em aterro industrial. Isto se agrava consideravelmente quando se trata de um material com densidades extremamente baixas na ordem de 20 a $30 \mathrm{~kg} / \mathrm{m}^{3}$. Isto significa que estes materiais ocupam um grande espaço nos aterros industriais e que dificulta a sua compactação agravando a solução do destino final destes materiais ${ }^{[3]}$.

Há estudos nesta área propondo destinos diferentes para estes resíduos, que são possibilidades de reciclagem e recuperação da PUR, incluindo tratamentos mecânicos ${ }^{[3-6]}$ e químicos ${ }^{[6-12]}$. A rota da reciclagem química por glicólise aplicada a espumas rígidas e flexíveis de poliuretano vem a cada dia se desmistificando e tem tomado espaço na literatura. No processo de glicólise as cadeias de poliuretano são degradadas em sucessivas reações de transesterificação da ligação uretano com polióis com o uso de solventes e catalisadores. A reação leva a conversão da espuma em reagentes numa mistura líquida de polióis e aminas aromáticas, que quando separados podem ser utilizados novamente como matéria prima em outros processos ${ }^{[6,8]}$. A Figura 1 mostra a reação de glicólise da espuma de poliuretano conforme Zia et al. ${ }^{\left[{ }^{[6]}\right.}$. A solubilização da espuma em solventes como o etilenoglicol (EG) ou o dietilenoglicol (DEG) e o uso de catalisadores como o acetato de potássio (KAc) e a dietanolamina (DEA) são aplicados em

Autor para correspondência: Daniela Becker, Departamento de Engenharia Produção e Sistemas, Universidade do Estado de Santa Catarina - UDESC, Rua Paulo Malschitzki, s/no, Campus Universitário Prof. Avelino Marcante, Bairro Zona Industrial Norte, CEP 89219-710, Joinville, SC, Brasil, e-mail: dep2db@joinville.udesc.br 


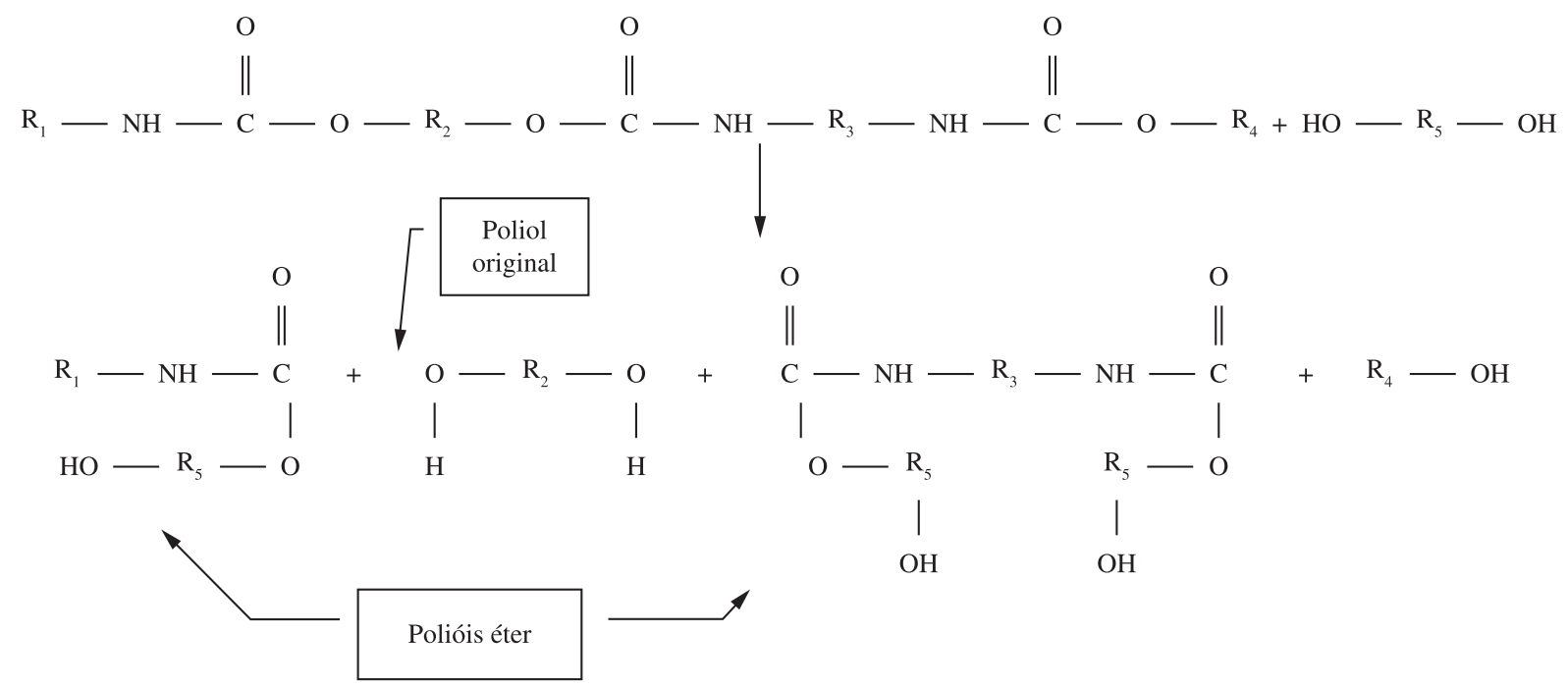

Figura 1. Formação de poliol éter como resultado do processo de glicólise (adaptado de ZIA et al. ${ }^{[6]}$ ).

temperaturas próximas de $200{ }^{\circ} \mathrm{C}$. As reações com tempo de duas horas têm demonstrado alto grau de conversões do grupo uretano, sendo assim uma alternativa viável tecnicamente com resultados próximos aos polióis puros ${ }^{[8-12]}$.

Também tem sido realizados estudos para a reutilização do poliol reciclado na obtenção de novas espumas. Prociak et al. ${ }^{[13]}$ investigaram as propriedades das espumas rígidas e flexíveis a partir de polióis recuperados por glicólise. Os glicóis utilizados foram o dietileno glicol sem a adição de catalisadores para viabilizar baixo custo. $\mathrm{O}$ produto apresentou número de hidroxilas entre 300-450 mg KOH/g. Nas espumas flexíveis a adição de poliol recuperado ficou limitada a $20 \%$. As espumas rígidas foram preparadas com $40 \%$ de poliol reciclado e apresentou condutividade térmica igual ou menor que espumas preparadas apenas com poliol virgem. Molero et al. ${ }^{[14]}$ estudaram a aplicação da parte superior do produto da glicólise obtido da espuma flexível de poliuretano. Todos os polióis reciclados e sem purificação posterior apresentaram grande contração e colapso da espuma. Concluíram que o uso de poliol reciclado e purificado por extração líquido-líquido adicionados ao poliol virgem em até $25 \%$ não causa prejuízo às propriedades físicas da espuma, e são comparáveis as espumas comerciais. Adições superiores a $25 \%$ reduzem a resiliência da espuma.

Este trabalho tem como objetivo realizar a reciclagem química, pelo processo de glicólise, da espuma rígida de poliuretano, reintroduzindo o poliol reciclado como parte da matéria prima no processo de espumação de componentes da indústria de refrigeração.

\section{Experimental}

\section{Matérias-primas}

No estudo proposto foram utilizados resíduos de espumas rígidas de poliuretano do processo de espumação da fábrica de refrigeradores da Whirlpool Latin America de Joinville-SC. A espuma tem como base poliol poliéter e difenilmetano diisocianato MDI e o cicloisopentano como agente de expansão física. Os resíduos da espuma foram lixados (Figura 2) e acondicionados em saco plástico e armazenamento.

Para reação de despolimerização foi utilizado o dietilenoglicol (DEG) da Vetec como solvente e o acetato de potássio (KAc), fornecido pela Synth, foi utilizado como catalisador. No processo de reespumação do poliuretano foi utilizado poliol poliéter da

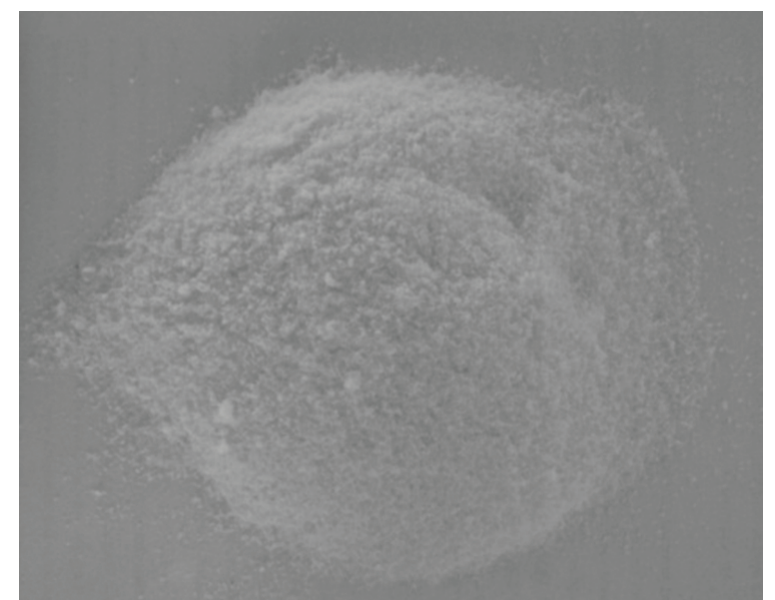

Figura 2. PUR moída preparada para reação química de despolimerização pela glicólise.

Dow Química, difenilmetano diisocianato (MDI) da Basf e o cicloisopentano da Solvay como agente de expansão física.

\section{Reação de despolimerização}

Diferentes concentrações de solvente e catalisador foram utilizadas no processo de glicólise, conforme Tabela 1. As concentrações da Tabela 1 foram determinadas a partir da massa de PUR utilizada. A reação foi realizada num balão de três bocas de $250 \mathrm{~cm}^{3}$ (Figura 3), com agitação mecânica e com velocidade variável entre 1000 e $1500 \mathrm{rpm}$, mantido numa temperatura de $200{ }^{\circ} \mathrm{C}$ por duas horas, contadas a partir da total solubilização do PUR. Os produtos da glicólise foram armazenados em recipientes fechados e identificados adequadamente para posterior avaliação.

\section{Caracterização do poliol reciclado}

O ensaio de viscosidade rotacional foi utilizado para caracterização reológica do poliol recuperado na temperatura de $25{ }^{\circ} \mathrm{C}$, utilizando um viscosímetro Brookfield, modelo MRVT 115 e spindle número 4 . O procedimento foi executado conforme norma interna Whirlpool NTW 80106 e ASTM D2196. Foi determinado o índice de hidroxilas de cada um dos produtos finais dos processos 
Tabela 1. Parâmetros utilizando na reação da glicólise de PUR avaliados a $200{ }^{\circ} \mathrm{C}$ e a $1 \mathrm{~atm}$.

\begin{tabular}{ccc}
\hline Reação & DEG (\% massa) & KAc (\% massa) \\
\hline 1 & 100 & 2 \\
2 & 100 & 5 \\
3 & 200 & 2 \\
4 & 200 & 5 \\
\hline
\end{tabular}

de glicólise por titulação conforme norma Whirlpool NTW 81434 e ASTM D 2849-1980. As análises da massa molar numérica média (Mn), massa molar ponderada média ( $\mathrm{Mw})$, bem como a distribuição de massa molar foram feitas por cromatografia líquida de alto desempenho (HPLC, modelo LC-20A, Shimadzu). O equipamento é provido de um detector RID-10A e injetor automático SIL-20A.

\section{Obtenção da espuma de PUR utilizando o poliol reciclado}

Após todas as caracterizações dos produtos reciclados, foi escolhido o poliol com menor índice de hidroxilas, conforme resultado da titulação, pois segundo $\operatorname{Vilar}^{[2]}$ número de hidroxila recomendável do poliol utilizado para produção de PUR é entre 300-800 mg KOH/g. Uma fração deste poliol foi misturada ao poliol virgem e adicionado ao processo de espumação para obtenção dos blocos de prova. A Tabela 2 mostra o planejamento experimental executado para obtenção da espuma com poliol reciclado.

Foi utilizado um molde de alumínio com aquecimento elétrico que possui características similares aos moldes de espumação de portas e gabinetes, para moldagem do bloco de prova. Do bloco foram retirados os corpos de prova para execução dos ensaios físicos, mecânicos e térmicos. O tempo de desmoldagem foi de 4 minutos após a espumação.

\section{Caracterização da espuma rígida de poliuretano}

A densidade do núcleo dos corpos de prova foi determinada por imersão conforme norma interna Whirlpool NTW01836 e NBR10:501.07-001/1. Para execução do ensaio foi utilizado um Becker com $2000 \mathrm{~mL}$ de água sobre uma balança de precisão. O corpo de prova foi totalmente imerso na água com o auxilio de um fino bastão metálico. A densidade do moldado (densidade teórica) foi determinada a partir da divisão numérica entre a massa de PU utilizada para obtenção do corpo de prova pelo seu volume, conforme norma interna Whirlpool NTW01836 e NBR10:501.07001/1.

Para determinação da condutividade térmica foi utilizado corpos de prova com dimensão de $200 \times 200 \times 40 \mathrm{~mm}$ e previamente acondicionados a $23{ }^{\circ} \mathrm{C}$ com umidade relativa de $55 \%$ durante 24 horas. Em seguida foram colocados entre duas placas mantidas a temperaturas diferentes, sendo uma fria a $10{ }^{\circ} \mathrm{C}$ e a outra placa quente a $38{ }^{\circ} \mathrm{C}$. A tensão fornecida ao equipamento para aquecer a placa quente foi ajustada até ser obtida condição de regime estacionário. Os ensaios foram feitos em aparelho do tipo Laser Comp modelo FOX 200. Os ensaios foram realizados conforme norma interna Whirlpool NTW 01898 e norma NBR12094.

A resistência a compressão foi determinada conforme norma interna Whirlpool NTB 01858 e ABNT NBR 8082. O equipamento utilizado foi uma máquina universal de testes Instron com velocidade do ensaio foi de $2,5 \mathrm{~mm} / \mathrm{min}$.

Para analise da formação das células da espuma foi utilizado um microscópio eletrônico de varredura modelo XL-30 marca Philips. As amostras foram cortadas e recobertas com uma fina camada de ouro em um equipamento Balzers modelo SCD-030.
Tabela 2. Planejamento e relação entre componentes para espumação com poliol reciclado.

\begin{tabular}{ccccc}
\hline Espumação & $\begin{array}{c}\text { poliol reciclado } \\
\text { (\% massa) }\end{array}$ & $\begin{array}{c}\text { Poliol } \\
\text { total (g) }\end{array}$ & $\begin{array}{c}\text { MDI } \\
\text { (g) }\end{array}$ & $\begin{array}{c}\text { CicloisoPentano } \\
\text { (g) }\end{array}$ \\
\hline V01 & 0 & & & \\
R 10 & 10 & & & \\
R 15 & 15 & 100 & 144 & 13,6 \\
R 20 & 20 & & & \\
\hline
\end{tabular}

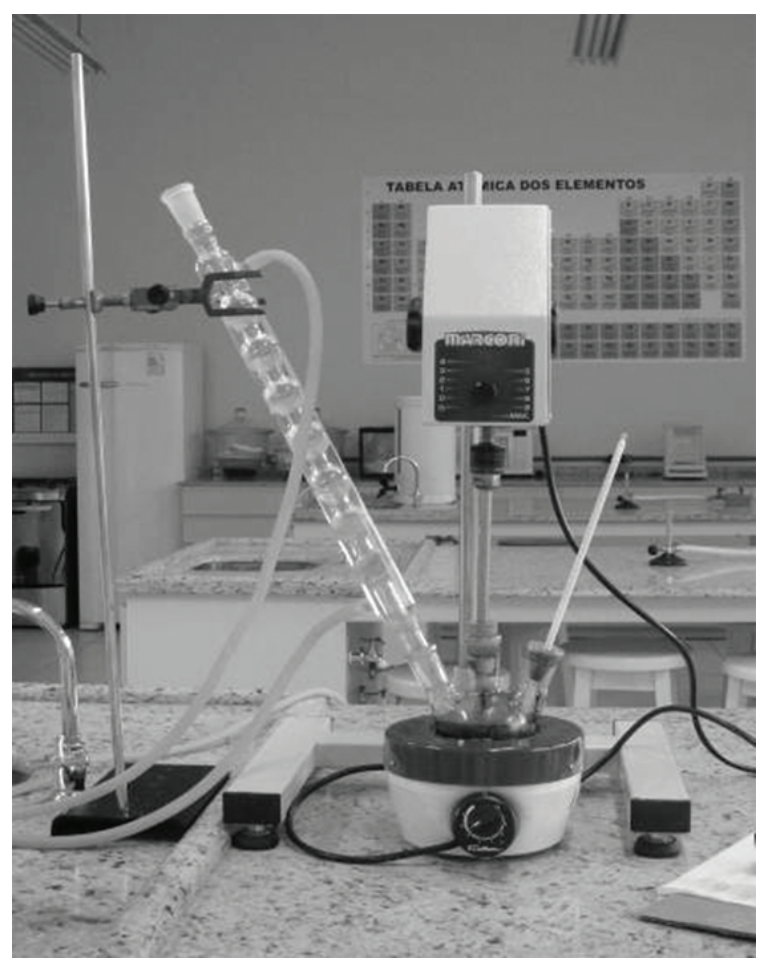

Figura 3. Equipamento utilizado para execução da reação de despolimerização.

\section{Resultados e Discussões}

\section{Caracterização do produto da glicólise}

Os produtos das reações de glicólise se apresentaram numa única fase líquida, viscosa e escura com algumas partículas pequenas dispersas. Aparentemente são resíduos de poliuretano que não reagiram e que foram retirados por processo de filtração simples. A Figura 4 mostra o produto da reação antes da filtração.

Os resultados obtidos na caracterização dos produtos das reações de glicólise são apresentados na Tabela 3. As reações 3 e 4 apresentaram menor viscosidade, devido ao excesso de DEG no poliol recuperado, que é um solvente de baixa massa molar com baixa viscosidade (26 m.Pa.s) e não se realizou a separação do DEG e do produto da glicólise. Os resultados encontrados são similares aos obtidos com a glicólise de poliuretano com poliol a base de óleo vegetal ${ }^{[15,16]}$. As reações 1 e 2 apresentaram valores maiores de viscosidade comparado com as reações 3 e 4, porém abaixo do poliol puro que apresentou viscosidade entre 3800-4000 m.Pa.s.

Os polióis reciclados mostram distribuição monomodal, apresentando valores para massa molar ponderada média $(\mathrm{Mw})$ entre 905 e 986 para todos os experimentos, com pequenas reduções quando aumentado a concentração de catalisador ou a relação DEG/ PU conforme Tabela 3. Segundo Wu et al. ${ }^{[8]}$ o aumento de catalisador 


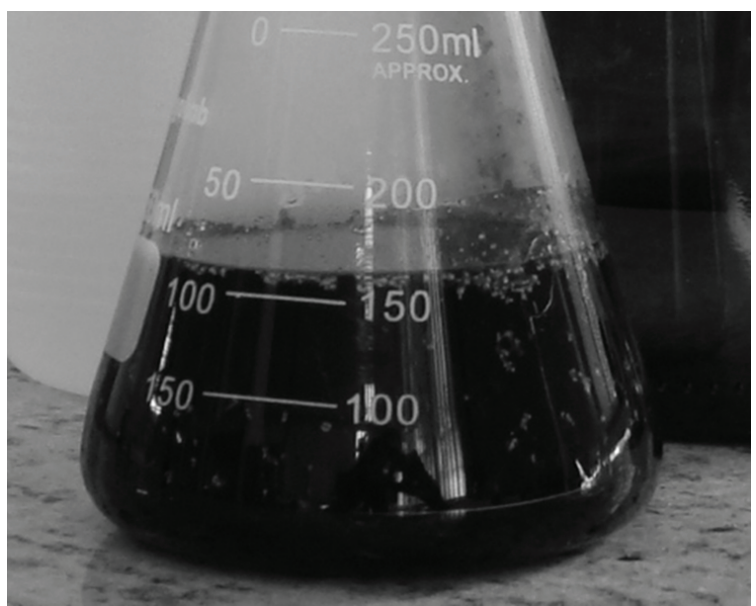

Figura 4. Poliol reciclado de resíduo de espuma rígida de poliuretano.

ou da relação mássica DEG/PU diminui a massa molar do produto, devido à entrada de DEG no lugar da cadeia carbônica do poliol. As polidispersões também apresentam pequenas variações. De maneira similar, Wu et al. ${ }^{[8]}$ e Murai et al. ${ }^{[10]}$ encontraram valores semelhantes para massas molares médias para reação de glicólise para espumas rígidas de poliuretano.

Os maiores valores de índices de $\mathrm{OH}$ são obtidos para as reações com maiores concentrações de DEG, que podem ser atribuídos ao solvente, pois apresenta em seu estado puro um índice de $\mathrm{OH}$ de $1057,3 \mathrm{mg} \mathrm{KOH} / \mathrm{g}^{[7,15]}$ que não foi separado dos produtos da glicólise (Tablea 3). O aumento da quantidade de KAc aumentou o número de hidroxilas, possivelmente pelas reações de transuretanização entre o poliuretano e o DEG. Segundo Fiorio et al. ${ }^{[16]}$ este comportamento pode estar relacionado com uma maior conversão dos grupos uréia em compostos com terminações em aminas primárias. Os valores encontrados nestes experimentos são similares a valores encontrados por $\mathrm{Wu}$ et al. ${ }^{[8,9]}$ e são maiores do que os valores encontrados por Molero et al. ${ }^{[7]}$ que promoveram a separação do produto da reação e o solvente utilizado como agente da glicólise. O poliol obtido na reação 1 foi utilizado para obtenção da espuma rígida de poliuretano, e assim avaliar a possibilidade de reutilização do mesmo na indústria de refrigeração.

\section{Caracterização das espumas rígidas de poliuretano}

Para caracterizar as espumas e garantir que as mesmas possam ser utilizadas na mesma aplicação comercial que já foram submetidos, suas propriedades mecânicas, físicas e térmicas foram avaliadas por métodos normalizados na indústria de refrigeração.

A Tabela 4 apresenta os resultados das densidades do moldado e do núcleo das espumas de poliuretano rígidas contendo poliol reciclado. A densidade do moldado e a densidade de núcleo apresentaram valores acima do mínimo requerido de $30 \mathrm{Kg} / \mathrm{m}^{3[2]}$ para a aplicação em refrigeradores, pois ela também tem a função de proporcionar estruturação mecânica ao produto. Para os ensaios com poliol recuperado observa-se que a densidade do núcleo é crescente com a quantidade de poliol reciclado. Este fato pode ser atribuído ao melhor empacotamento da espuma e maior velocidade de reação de polimerização, devido à maior concentração de hidroxilas conforme observado nos ensaios de titulação. Shendijarevic ${ }^{[17]}$ também observou que pequenas porcentagens de poliol recuperado levam a uma redução da densidade e altas porcentagens aumentam a densidade.

A condutividade térmica dos corpos de prova é apresentada na Tabela 5. Para os testes de condutividade térmica, quanto menor
Tabela 3. Caracterização dos produtos obtidos dos experimentos de glicólise.

\begin{tabular}{ccccc}
\hline Reação & $\begin{array}{c}\text { Viscosidade } \\
\text { (m.Pa.s) }\end{array}$ & $\begin{array}{c}\text { Titulação } \\
(\mathbf{m g ~ K O H} / \mathbf{g})\end{array}$ & \multicolumn{2}{c}{ Massa molar } \\
\cline { 4 - 5 } & & 389 & 872 & Mw/Mn \\
\hline Poliol & 4000 & 752 & 986 & 1,16 \\
1 & 1100 & 789 & 979 & 1,26 \\
2 & 1300 & 815 & 914 & 1,19 \\
3 & 300 & 877 & 905 & 1,20 \\
4 & 250 & & &
\end{tabular}

Tabela 4. Densidade moldada e densidade do núcleo dos blocos espumados.

\begin{tabular}{ccc}
\hline Reações & Densidade moldada $\mathbf{~} \mathbf{g} / \mathbf{m}^{\mathbf{3}}$ & Densidade do núcleo $\mathbf{~ K g} / \mathbf{m}^{\mathbf{3}}$ \\
\hline V 01 & 36,9 & 31,9 \\
R 10 & 36,4 & 32,6 \\
R 15 & 38,4 & 33,3 \\
R 20 & 39,5 & 34,6 \\
\hline
\end{tabular}

o valor obtido melhor a propriedade de isolamento térmico do material. Os valores encontrados estão dentro da faixa de valores indicados em literatura $(18-23 \mathrm{~mW} / \mathrm{mK})^{[2]}$, e similar ao valor encontrado para a espuma comumente utilizada na aplicação de refrigeração. As variações encontradas entre os resultados estão dentro dos limites de tolerância de $\pm 1 \mathrm{~mW} / \mathrm{mK}$ aceita na indústria de refrigeração conforme norma interna NTW-01898- Determinação da condutividade térmica da espuma rígida de poliuretano utilizada para isolamento térmico.

Os resultados de resistência a compressão para $10 \%$ de deformação são apresentados na Tabela 6 . Todos os valores obtidos para a resistência a compressão atendem a especificação mínima de $130 \mathrm{KPa}$ requeridos para estruturação mecânica de refrigeradores ${ }^{[2]}$. Os resultados obtidos estão dentro da faixa de tolerância mínima de $10 \%$ entre amostras. As diferenças nos resultados de resistência a compressão pode estar relacionada com a presença de resíduos de baixas massas molares no poliol reciclado e variações na composição da cadeia polimérica do PUR devido à adição do poliol recuperado, incluindo grau de reticulação e domínios rígidos ${ }^{[14]}$.

Os blocos de prova obtidos das espumações foram cortados e analisados por microscopia eletrônica de varredura, conforme Figura 5. Observam-se diferentes empacotamentos das células fechadas para diferentes concentrações de poliol. A Figura 5a ilustra o empacotamento da espuma com poliol $100 \%$ virgem. Observa-se um tamanho médio de células esféricas variando de 200 a $300 \mu \mathrm{m}$, revelando um adequado empacotamento celular e homogeneidade na distribuição do material, com espessura da parede uniforme do esqueleto polimérico. Segundo Vilar ${ }^{[2]}$, uma espuma rígida típica de poliuretanos, com densidade de $32 \mathrm{~kg} / \mathrm{m}^{3}$, consiste em mais de $95 \%$ do volume da espuma de poliuretano seja composta pelo agente de expansão físico e químico, minimizando assim a transferência de calor através da estrutura polimérica.

As micrografias as espumas contendo poliol reciclado (Figura 5b, c, d) apresentam uniformidade estrutural, com superfícies lisas e bem definidas. Porém é possível observar que as algumas paredes das células estão quebradas, que podem ser decorrentes da estrutura do poliuretano durante a formação da espuma nas fases líquida, gel e cura ${ }^{[18]}$ ou durante o corte na preparação da amostra. A Figura $5 b$ apresenta a micrografia da espuma com a utilização de $10 \%$ de poliol reciclado. A micrografia mostra células arredondadas, com uniformidade de tamanhos que variam entre 150 e $250 \mu \mathrm{m}$ muito similares a espuma com poliol $100 \%$ virgem. Os resultados obtidos para condutividade térmica, resistência a compressão, densidade de núcleo da espuma com $10 \%$ de poliol reciclado validam para utilização como isolamento 


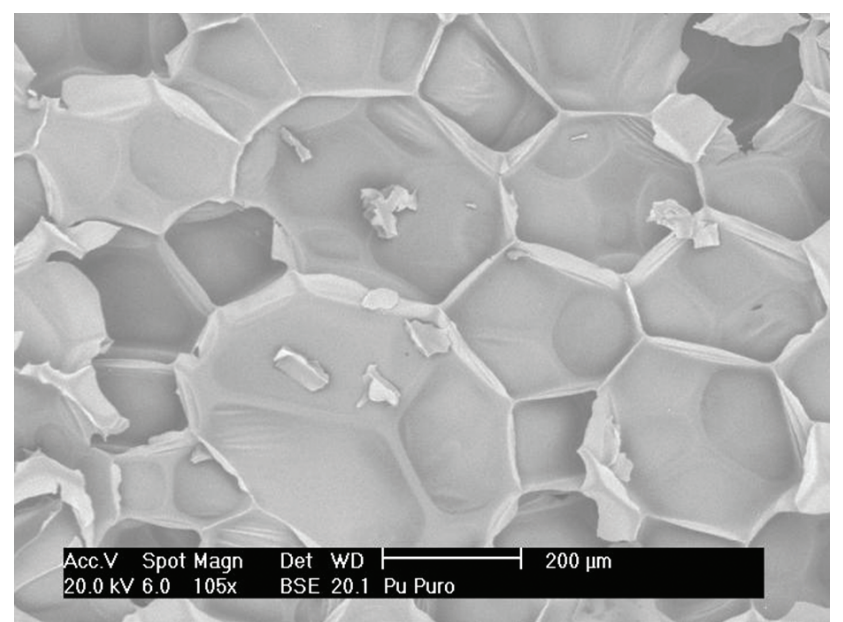

(a)

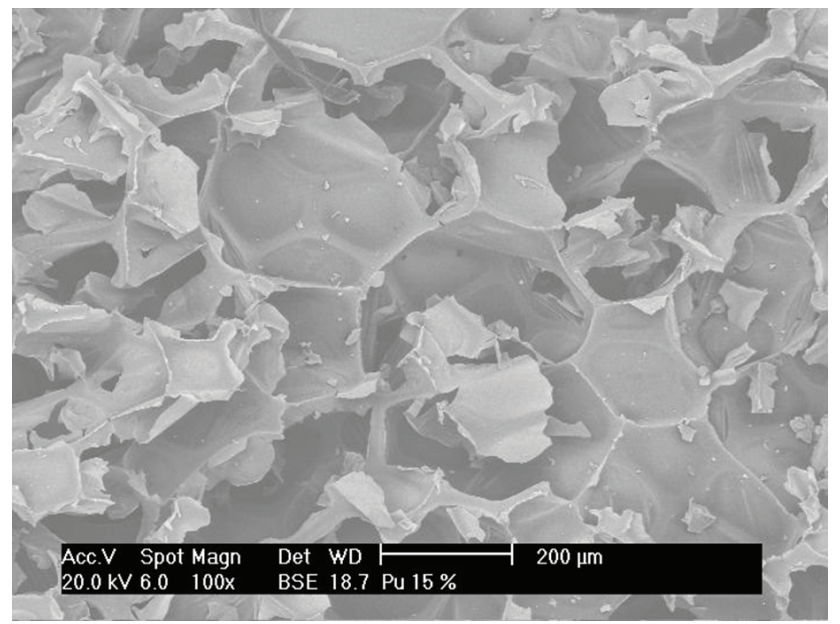

(c)

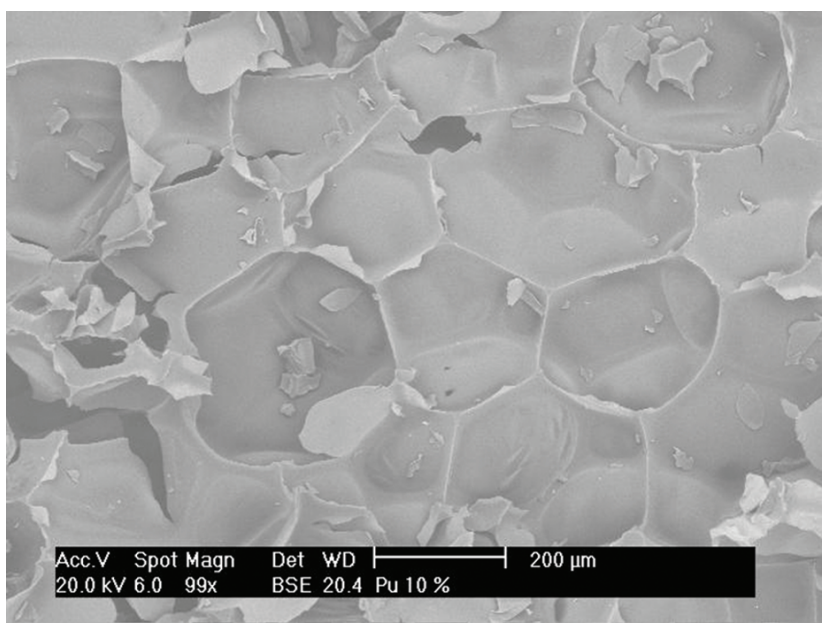

(b)

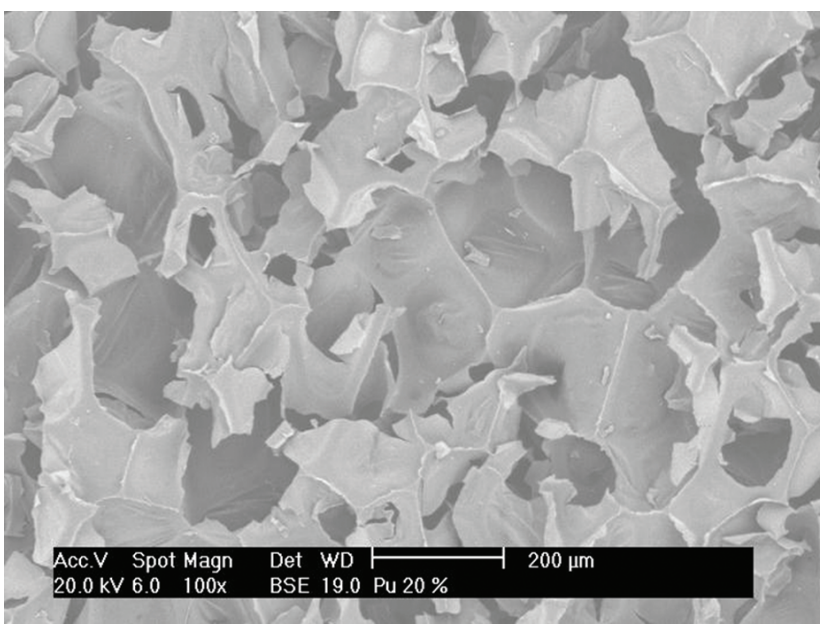

(d)

Figura 5. Micrografia da fratura da espuma de PU: a) com poliol 100\% virgem; b) com 10\% de poliol reciclado; c) com 15\% de poliol reciclado; d) com 20\% de poliol reciclado.

Tabela 5. Resultados de condutividade térmica das espumas de PU com poliol virgem e poliol reciclado.

\begin{tabular}{cc}
\hline Reações & Condutividade térmica $(\mathbf{m W} / \mathbf{m K})$ \\
\hline V 01 & 20,7 \\
R 10 & 21,0 \\
R 15 & 20,5 \\
R 20 & 20,8 \\
\hline
\end{tabular}

Tabela 6. Resultados de resistência a compressão das espumas de PU preparadas com poliol virgem e com poliol reciclado.

\begin{tabular}{cc}
\hline Reações & Resistência a compressão (KPa) \\
\hline V 01 & $167 \pm 1,4$ \\
R 10 & $195 \pm 8,5$ \\
R 15 & $166 \pm 5,0$ \\
R 20 & $192 \pm 2,1$ \\
\hline
\end{tabular}

térmico e estruturação mecânica para utilização na produção de refrigeradores. Observa-se também um empacotamento homogêneo das células. Não se observa diferença significativa na morfologia das células nas amostras da Figuras 5a, b.

As Figuras 5c, d apresentam as micrografias das espumas com 15 e $20 \%$ de poliol reciclado, respectivamente. A estrutura celular da amostra apresenta-se quebrada, evidenciando a ação de forças sobre a amostra. Para esta amostra poderá haver perdas nas características térmicas da espuma ao longo de sua utilização, pois apresenta células rompidas.

\section{Conclusões}

O processo de reciclagem química por glicólise aplicado a resíduos de espuma rígida de poliuretano viabiliza uma rota ambientalmente e socialmente adequada para o destino destes materiais. Resíduos de espuma rígida de poliuretano podem ser reciclados e reintroduzidos no processo de fabricação de refrigeradores domésticos.

Nas condições estudadas, sugere-se o percentual em até $10 \%$ de poliol reciclado misturado ao poliol virgem, pois não haverá prejuízos para aplicação em refrigeração. A condutividade térmica da espuma, a resistência a compressão, densidade de núcleo e sua morfologia apresentaram-se adequados para os padrões industriais atuais. Espumas que utilizam até $20 \%$ de poliol reciclado podem ser utilizadas em aplicações menos nobres ou para preenchimento de peças de engenharia e no isolamento de residências com base nos resultados de resistência a compressão, condutividade térmica e estabilidade dimensional. 


\section{Agradecimentos}

Os autores agradecem a Whirlpool Latin America pelo apoio na realização deste trabalho.

\section{Referências Bibliográficas}

1. Carvalho, C. A. - "Avaliação da reciclagem de poliuretano como carga no próprio processo de injeção", Dissertação de mestrado, Universidade da Região de Joinville, Brasil (2008).

2. Vilar, W. D. - "Química e Tecnologia de Poliuretanos", Rio de Janeiro (2001).

3. Bom, R. P. - Rev. Mater.,13, p.388, (2008).

4. Rosa, S. D. \& Guedes, C. G. F. - Polímeros, 13, p.64 (2003).

5. Becker, D.; Roeder, J.; Oliveira, R. V. B.; Soldi, V. \& Pires, A. T. N. - Polym. Test., 22, p.225 (2003). http://dx.doi.org/10.1016/S01429418(02)00086-7

6. Zia, M. K.; Bhatti, N. H. \& Bhatti, A. I. React. Funct. Polym., 67, p.675 (2007). http://dx.doi.org/10.1016/j.reactfunctpolym.2007.05.004

7. Molero, C.; Lucas, F. \& Rodríguez, J. F. - Polym. Degrad. Stabil., 91, p.894 (2006). http://dx.doi.org/10.1016/j.polymdegradstab.2005.06.023

8. Wu, C. H.; Chang, C. Y. \& Li, J. K . - Polym. Degrad. Stabil., 75, p.413 (2002). http://dx.doi.org/10.1016/S0141-3910(01)00237-3

9. Wu, C. H.; Chang, C. Y.; Cheng, C. M. \& Huang, H. C. - Polym. Degrad. Stabil., 80, p.103 (2003). http://dx.doi.org/10.1016/S01413910(02)00390-7

10. Murai, M.; Sanou M.; Fugimoto T. \& Baba F. - J. Cell. Plast., 39, p.15 (2003). http://dx.doi.org/10.1177/002195503031021
11. Molero, C.; Lucas, A.; Perez, C. \& Rodriguez, J. F. - Proceedings of the Global Symposium on Recycling, Waste Treatment and Clean Technology, 2, p.1681, Madri (2004).

12. Modesti, M. \& Simioni, F. - Polym. Eng. Sci., 36, p.2173 (1996). http://dx.doi.org/10.1002/pen.10614

13. Prociak, A. \& Pielichowski, J. - Proceedings of the Global Symposium on Recycling, Waste Treatment and Clean Technology, 3, p.2351, Madri (2004)

14. Molero, C.; Lucas, A.; Romero, F. \& Rodríguez, J. F. - J. Appl. Polym. Sci., 109, p.617 (2008). http://dx.doi.org/10.1002/app.28136

15. Menger, R. K.; Veronese, V. B. \& Petzhold, C. L. - "Reciclagem de espumas rígidas de poliuretano a base de óleo vegetal", in: Anais do $10^{\circ}$ Congresso Brasileiro De Polímeros, Foz do Iguaçu - PR, out (2009).

16. Fiorio, R.; Kich, V. F.; Grisa, A. M. C.; Zeni, M. \& Zattera, A. J. - Rev. Iberoam. Polim., 11, p.134 (2010).

17. Shendijarevic, V. - "Chemical recycling of mixed polyurethane foam stream recovered from shredder residue into polyurethane polyols", in: Proceedings of the Polyurethanes 2004 Conference, Las Vegas - NV (2004).

18. Bolsoni, E. - "Estudo do reaproveitamento e reutilização das espumas rígidas de poliuretano pós-consumo", Tese de doutorado, Universidade Federal do Paraná, Brasil (2008).

Enviado: $25 / 02 / 11$ Reenviado: $30 / 05 / 11$ Aceito: 07/08/11 